\title{
Tweaking Harassment Through Tweets: A Critical Discourse Study of \#MeToo
}

\author{
Amir Akhtar $^{1}$, Liu Kanglong ${ }^{2}$, Tahira Jabeen ${ }^{3} \&$ Muhammad Afzaal $^{4}$ \\ ${ }^{1}$ Assistant Professor, Department of English, Foundation University Rawalpindi Campus, Pakistan \\ ${ }^{2}$ The Hong Kong Polytechnic University, Hong Kong \\ ${ }^{3}$ Foundation University Rawalpindi Campus, Pakistan \\ ${ }^{4}$ Institute of Corpus Studies and Applications, Shanghai International Studies University, China \\ Correspondence: Muhammad Afzaal, Institute of Corpus Studies and Applications, Shanghai International \\ Studies University, China. E-mail: muhammad.afzaal1185@gmail.com
}

\author{
Received: October 5, 2019 Accepted: November 3, 2019 Online Published: December 15, 2019 \\ doi:10.5539/ijel.v10n1p157 URL: https://doi.org/10.5539/ijel.v10n1p157
}

\begin{abstract}
The study aims to conduct an analysis of the discourse on \#MeToo which the study takes to be the unmediated voice of the victims of sexual harassment to determine the ideology imbibed in the discourse. Teun A. van Dijk's Ideology and discourse: A multidisciplinary introduction (2000) serves as the theoretical basis for the study as it attempts to categorize what constitutes harassment for the victims by looking at 3000 tweets posted over thirty days. The critical analysis of the data reveals that one of the most lacking elements in the life of the victims of sexual harassment is an acknowledgment of harassment as harassment. Most of the victims are abused, shamed and silenced when they try to share their panic experiences of life. The study shows that sexual harassment is a widespread social epidemic and can occur to a person of any age group, at any place and in any type of relationship. The study is significant as it presents the unmediated view of the victims of sexual harassment and compares it with the existing view of harassment. The significance of the study also lies in the fact that it analyzes the features of Twitter to determine their role in shaping the discourse. Previous studies on harassment talk about the issue or explore its features and types through various angles, but none of them focuses on the voice of the victims themselves.
\end{abstract}

Keywords: harassment, \#MeToo, voice, perspective

\section{Introduction}

The year 2017 would always be remembered for its emphasis and media attention on harassment as a social plague. The inauguration of Donald Trump turned out to be a media event for the wrong reasons and was billed as a worldwide political "earthquake" and a "catastrophe" (The Guardian, 2016) due to his brazen style of politics and also the misogyny that litters his public and political career. Naturally, women's rights groups were at the forefront of the campaign against Trump as millions rallied against Trump's being elected as the president of the United States (Malone \& Gibson, 2017). It meant sexual harassment was being talked about as never before. Even in conservative countries like Pakistan, the media discussed Trump's sexual liaisons and inappropriate passes and mainstreamed them. Though Trump denied all allegations by calling it "fake news" and did not take responsibility for any of the alleged acts (Shah, 2018) the allegations had a wide backlash which even as the third year of his Presidency is starting has not let up.

Amidst all this media discussion about sexual harassment, a greater revelation jolted nearly everyone out of their slumber and got them to take notice of the pervasiveness of harassment like never before. The accusations made by the famous actress, model, and social activist, Alyssa Milano, against Harvey Weinstein, founder of the famous Miramax and Hollywood mogul, who attempted to assault her sexually during an official meeting provided impetus to the activism against women's harassment. Milano tweeted \#MeToo on 15-10-2017 and encouraged all the victims of sexual harassment to tweet the same hashtag to register their protest against sexual abuse and to express solidarity with other victims of sexual harassment. It reignited the social movement "MeToo: Empowerment through Empathy" started by a Black social activist Tarana Burke in the pre-hashtag era in 2006. The aim of this movement was to bring the victims out of their sense of isolation and show that "radical 
healing" was possible (Singh, 2017). Sexual harassment as defined to be an "unwanted or offensive sexual attention, suggestion or talk" in Cambridge Dictionary (n.d.) and "a form of discrimination" that "involves any unwanted physical or verbal behavior that offends or humiliates" (Canadian Human Rights Commission [CHRC], n.d.) has assumed the shape of a social epidemic. The Protection Against Harassment of Women at the Workplace Act (2010) defines "harassment" as an "unwelcome sexual advance, request for sexual favors or other verbal or written communication or physical conduct of a sexual nature or sexually demeaning attitudes" that intimidates or creates a hostile work environment. Milano's hashtag brought about an unprecedented response and the victims of sexual harassment used the hashtag as a platform to express their pent-up emotions and share their ordeals, and stories of survival. More than half a million tweets were made within twenty-four hours of the tweet by Milano. Singh (2017) informs that over 1.7 million tweets contained the \#MeToo and the Twitter moment turned into a movement against social inequality and gender bias. It is noteworthy that the victims did not include only women, but men and transgenders.

As a follower of this scenario and a student of linguistics, my interest in the topic kept growing considerably. The power of language attracted me and I found a great opportunity here to go deep into the discourse created on \#MeToo and look for what actually the victims want to give voice to through this discourse. We saw here an opportunity to access the discourse in probably as pure a form as possible. It seemed to be full of scope for a deep exploration under the textual cover of the discourse on \#MeToo.

The Twitter moment turned into a real voice of the victims and assumed considerable significance. It seemed to be the voice of all the victims "suffering in silence" (Scott, 2017). It appeared as an awareness and reckoning campaign against sexual harassment. Societies, whether conservative or liberal, have tended to consider sexual harassment a taboo, a topic that must be hushed up. \#MeToo started a conversation about it to get rid of the mystery attached to it. Through their engagement with the hashtag, the victims gave a clear message that they would not tolerate sexual harassment any more. This conversation definitely "headed towards a solution" (Loveday, 2017). \#MeToo has taken the topic out of the realm of taboo and made it something very important to be talked about. \#MeToo and the following discussion offered a wonderful opportunity to study harassment and understand the issue from the victims' perspective. The study was informed by the Socio-Cognitive Theory and tried to unveil the subtle relationship between discourse and society. The textual analysis focused on theoretical underpinnings and ideological imprints the discourse was imbibed with.

The purpose of the research was to study the perspective of the victims of sexual harassment and characterize the ideology exhibited therein. The study also explored the way victims feel about harassment and what they want to be done about it.

Van Dijk's Discourse and ideology: A multidisciplinary introduction (2000) served as the basis for critical analysis of the discourse on \#MeToo. Van Dijk (2000) believes that ideologies are "expressed, constructed or legitimized by discourse" (p. 5). Ideologies are the pivotal beliefs of a group or its members regarding social, political, or religious issues shared by the members of a social group monitoring their social practices. Discourses are also an example of social practices influenced by certain ideologies that further create and mold ideologies. Discursive aspects of ideologies are very important as they clarify how ideologies are expressed, concealed, or reproduced in society. Every ideology has a counter-ideology and both include certain humanitarian aspects in them (Van Dijk, 2000).

According to Van Dijk, cognition becomes a link between discourse and society, thus creating a triangular relationship among discourse, cognition, and society. People living in a social group possess personal and socially shared beliefs that they understand each other and form a collective social memory. A huge body of knowledge usually shared by all the intellectuals of society and not professed unless a newcomer enters that group is called the common ground of that social group. These opinions and knowledge are also part of the socially shared memory (Van Dijk, 2000).

The members of a social group may have multiple ideologies and sub ideologies simultaneously. Their social representations are based on certain ideologies that have a certain schematic structure based on ideas about identity, norms values, and goals, etc. discourse gives expression to ideologies. There can be a movement from discourse to ideology and vice versa that shows that ideologies and discourses are interconnected (Van Dijk, 2000).

\section{Literature Review}

The literature review is built around the organizing principle of looking at the existing literature on \#MeToo, studies on sexual harassment, and studies that use Van Dijk's Socio-Cognitive theory to arrive at the gap for the present study. The study also uses the literature review to shape the study in terms of data collection and the 
method of research.

\subsection{Studies on \#MeToo}

\#MeToo got viral and was given coverage globally by renowned news organizations like CNN and Huffington (\#MeToo, n.d.). BBC and CNN broadcast the struggle of the victims of sexual harassment to dismantle the structure of power abuse in society. Aljazeera did not give that much coverage to \#MeToo that reflects its ideological perceptions about the creation of the hashtag (Nuraddin, 2018). Time magazine gave these victims of sexual harassment a title of "the silences breakers" and awarded them the title of Person of the year in recognition of their bravery and courage to survive in odd circumstances and to speak up to show solidarity with all other victims (Bever, \& Ohlheiser, 2017).

\#MeToo has appeared as an awareness campaign and has created a stir in various fields of life. It has spread awareness about the exploitative workplace culture and has emphasized the need to implement rules present in the books of law. It led prosecutors to fight for the rights of the victims (Heymann, \& Vogelstein, 2017) and many cases were filed against high profiled personalities, e.g. media mogul Harvey Weinstein, Fox host Bill O'Reilly, Head of Amazon Studios, Roy Price, and Vox Media editorial director, Lockhart Steele, etc. (Carlsen et al., 2018).

\#MeToo not only stirred a movement in the United States but all over the world. It caught a global momentum and encouraged the victims to speak up against harassment (Burke, 2018). Different people raised allegations in Japan, China and even conservative countries like Pakistan. It encouraged women to speak against the pervasive problem and reject the culture of silencing the victims (Mehmood, 2018). Many famous Pakistani women like Ayesha Gulalai, Nighat Dad, and Nadia Jamil shared her painful memories of sexual abuse (Jahangir, 2018).

The creation of \#HowIWillChange supports the victims of sexual abuse and shows a belief in the need for a better and inclusive society for all. Some people showed their grievances on \#HowIWillChange as they felt they were accused of bringing on what happened to them and they saw the existence of "rape culture" denied (PettyJohn et al., 2018). The creation of \#MeToo is seen as an "authentic contribution to social activism" by many people (Wood, 2018) and is considered being the founding step for a collective shift towards a "more just society" (Mendes et al., 2018). It has given rise to an overdue awareness about workplace culture, rights of the employees to have a better and safe work environment and a need to reject and report harassment of any kind (Heymann \& Vogelstein, 2017). It has encouraged medical professionals as well to ponder over the biased work environment and gender discrimination and a dire need to promote equity and respect for everyone (Holroyd-Leduc \& Straus, 2018).

Feministic perspective shows a split about views on \#MeToo. The youngsters found it to be "most high profile" instance of social media activism (Mendes, Ringrose, \& Keller, 2018) that is a tool to dismantle and challenge power imbalance in society (Rümmelein, 2018) while the older generation takes it to be "puritanical" (Burke, 2018) and thinks that it portrays women as "a helpless object of men's desire" (Astier, 2018).

The political perspective of \#MeToo shows its significant impact on political affairs. In an interview to Carlson (2017), Mr. Pearson, a political science professor at the University of Minnesota confirmed the "significant" effect of \#MeToo on political affairs and Myer Siemiatycki, a political science professor at Ryerson said, as mentioned by Nanji (2018), the movement led "men generally and of course ... women, to think enough is enough, and [that they] need more women to run for political office".

There has been a harsh criticism of the creation and effects of \#MeToo. The posters have been accused of being false accusers trying to make themselves "significant" NowThis (2018). Some of them argued that \#MeToo has created an environment of threat and insecurity among employees. The employers now want to hire men instead of women calling \#MeToo "a classic moral panic" (Smith, 2018).

\subsection{Studies on Harassment}

Sexual harassment is recognized as "a form of discrimination and violence against women" (UN Women, n.d.) by The United Nations. It includes any unwanted "sexual advance, request for sexual favor, verbal or physical conduct or gesture of a sexual nature" (UN Women, n.d.). Stanford University (n.d.) defines harassment in its policy as "unwelcome sexual advances, requests for sexual favors, and other visual, verbal or physical conduct of a sexual nature". Though this definition is workable, only such behavior affects academic or employment decisions in a university activity. Harassment is a type of aggressive behavior that includes "unwanted sexual attention, and sexual coercion" (Barak, 2005). It is also considered work-related action that aims at achieving some "valued personal goals" (O’Leary-Kelly, Paetzold, \& Griffin, 2002).

Sexual harassment is nothing new, and it is firmly ensconced in our society" (Woods, Buchanan, \& Settles, 
2009). Even in academic setups, students are faced with harassment by the seniors, peer groups and supervisors, and female victims have been found less inclined to share their experiences (Ayres, Friedman, \& Leaper, 2009). According to a survey conducted by European Foundation for the Improvement of Living and Working Conditions in 2000 , "about $12 \%$ of the employed in education and health sector in EU member states experienced some form of harassment at work" (Russo, Milić, Knezević, Mulić, \& Mustajbegović, 2008) and that is thought to affect workers' productivity (Kisa, Dziegielewski, \& Ates, 2002).

Sexual harassment includes, but may not be not limited to, "Catcalling, receiving unsolicited sexual pictures and suggestive comments" ( $\mathrm{Wu}, 2016)$ and the harm of street remarks is far-reaching (Bailey, 2017). Online harassment is getting very common and according to a Pew Research Center report from 2014, as mentioned by $\mathrm{Wu}$ (2016), " 25 percent of young women and 13 percent of young men in the U.S. had been sexually harassed online".

Different policies have been framed by academic and professional institutions to prevent harassment and ensure an inclusive environment. The responsibility to prevent harassing attitudes also lies with the employees who need to discourage and report such behavior EEOC (n.d.). Online courses are also offered by the universities to instruct the students how to avoid any behavior that makes them uncomfortable (Pilgram, \& Keyton, 2004).

Different law enforcing agencies have framed laws against the perpetrators. There are different legal definitions that can help people discriminate between normal and harassing behavior. Australian law includes The Sex Discrimination Act 1984 defines sexual harassment to be "unwanted conduct of a sexual nature" (HRMP, n.d.). French Criminal Code recognizes harassment and expects that harassment occurs only among power relationships and Danish law also defines sexual harassment and includes it in its workplace policies. In India and Poland, sexual harassment is recognized but there are no specific laws against workplace sexual harassment (HRMP, n.d.).

United Kingdom, Russia, Switzerland, and the United States have specific laws against sexual harassment. In the US, there are several options for the complainant to file a case with the Equal Employment Opportunity Commission (EEOC) and Fair Employment Practice (FEP) (HRMP, n.d.).

In Pakistan, there is a legalized and well-defined Code of Conduct for gender justice in the workplace and sexual harassment. "Section 509 of the Pakistan Criminal Penal Code and the Protection Against Harassment of Women at the Workplace Act of 2010" (Jatoi, 2018) are two options to find recourse against harassment. Alliance Against Sexual Harassment At workplace (AASHA) defines sexual harassment in line with the US's definition of it. The problem and barrier in the way to implementation of these laws is the lack of trained staff and people's unawareness of these laws (Jatoi, 2018). Moscow Center for Gender Studies reports that, actually, such cases are not taken up by the courts (HRMP, n.d.). There are still 24 countries in the world with laws against protection against sexual harassment at workplace and 235 female workers are left with no legal recourse (University of California, Los Angeles, 2017). Even the US law lacks proper implementation (Heymann \& Vogelstein, 2017).

Harassment adversely affects the victims' physical, psychological and professional life (Munson, Hulin, \& Drasgow, 2000; Hoosain, 2017; Bergman, Langhout, Palmieri, Cortina, \& Fitzgerald, 2002; Harned, Ormerod, Palmieri, Collinsworth, \& Reed, 2002).

\subsection{Application of T. A. van Dijk's Socio-Cognitive Model}

Many researchers have conducted studies with the Socio-Cognitive model as a conceptual framework. Ana (1997) merged it with Lakoff's metaphor theory to study anti-immigrant newspaper discourse, and Chiluwa (2012) studied political resistance on social media networks. Bilal, Ahsan, Gohar, Younis and Awan (2012) deduced discursive features used as ideological strategies from political talk shows, Azad (2013) investigated news broadcasting discussing the US president G. W. Bush, Alo and Orimogunje (2013) talked about ideological bias in radio news and Ghachem (2015) analyzed political speeches. Pasha (2011) critically analyzed Egyptian and Ahmadian and Farahani (2014) studied Iranian/American newspapers to explore ideological underpinnings in the discourse. Nurrudin (2018) investigated the ideological perspective behind the extensive media coverage of \#MeToo. Golmohammadi, Suluki, Daneshmand and Salahshoor (2014) and Ramanathan and Tan (2015) studied research articles using Van Dijk's Socio-Cognitive perspective.

The data for this study which attempts to characterize the victims' perspective on sexual harassment through the discourse on \#MeToo was taken from Twitter posts sharing the experience of sexual harassment. A sample of 3000 tweets was retrieved from Twitter on \#MeToo spanning thirty days divided into three different phases. The tweets in the sample were taken without any filter of gender, age or region. Only language filter was used and 
tweets in only English language were collected. Posters' ID was also saved to make data retrieval more feasible. The tweets were thematically categorized into 19 different categories that helped to analyze multiple tweets belonging to a category simultaneously. The categories were further shrunk on the basis of related themes and finally, 6 broad categories were formed for critical analysis to dig out the ideological patterns present in the discourse created by the victims of sexual harassment.

At the first stage, textual analysis was conducted that provided a basis for critical discourse analysis of the data.

\section{Analysis and Discussion}

Discourse on \#MeToo shows that there is a common denial of harassment and the unlawful act of sexual abuse is not acknowledged to be a wrongdoing. Even when the action is acknowledged it is considered a non-event. The victims' perspective is abundantly clear that whenever they confided into their parents, friends or authorities on campus, they met with distrust. Genee (2017) tells her mother did not "listen" to her when she tried to share her painful experience of harassment. The victims are not trusted when they share their stories and are accused of "lying for attention" Carla the Viking (2017). Researches show that the traumatic experiences of the victims are downplayed and there is a "tendency to underplay" the act of sexual harassment that results in giving "undue concession" to the perpetrators (Sahgal \& Dang, 2017). The victims' perspective on harassment is that the act of harassment should be acknowledged as harassment and should not be shrugged off by calling it a fabricated story.

Sexual harassment can range from verbal harassment like "catcalls" (Claudia, 2017) and "sexual comments" (Lindahl, 2017) to the physical contact of sexual nature like Lanece's (2017) butt "grabbed" by a boy and rape. The inappropriate sexual advances are at times completely ignored by the society and taken to be normal that is why the consensus on them being harassment eludes the society. Researches elucidate that sexual harassment can occur in various environments. Young students may attempt to develop "sexualized contact" (Witkowska, 2005) in academic settings and there are equal chances for harassment to occur in offices, public places and even in public transport.

The tweets inform that drinking is one of the most common acts leading to sexual activities. It opiates the intellectual abilities of a person and makes him breach the trust of even a very close and dear friend. Sometimes a willing consumption by one or both partners leads to an abusive act. The victims can also succumb to it as Mitchell (2017) went to a "dinner party at an acquaintance's house, got drunk". Sometimes it is forced consumption of alcohol as Martinez (2017), was drugged by "a friends' cousin... at a party and raped". Abbey (2002) believes that the current discourse does not go to the extent of linking alcohol use directly with rape but finds it conducive to rapes and sexual abuse when consumed on social gatherings and parties (Abbey, 2002). It also hints to the perspective of the victims that alcohol sometimes becomes a facilitator of sexual abuse.

Sexual harassment is not only a problem in female majority environments but also in male majority environments. It's faced by girls and boys students (Witkowska, 2005). Faculty and administrative staff can also fall prey to sexual harassment. Suppression of such experiences or not reporting it can cause depression and many health issues (Marsh et al., 2009). With technological advancement, there are instances of online harassment as well. Many times, online friendships culminate in "virtual rape" (Döring, 2000). Victims" perspective here is that harassment is like a social epidemic and rampant. The horrific pervasiveness of this issue shows that it is ignored and needs to be controlled conscientiously to protect the basic right to live for all humans.

Harassment can be practiced by peers, coworkers, people in a powerful position and strangers, etc. Low ranked people have more chances to be exploited by their superiors (Sahgal \& Dang, 2017). The victims feel betrayed and disappointed by every relationship they are in and develop a feeling of insecurity.

Recounting the experience of sexual harassment is usually stigmatized, and the victims ostracized. There is a common attitude towards reporting these incidents. The victims are advised to get on with such experiences and not attach importance to them. Some are bullied to remain tight-lipped to avoid threats to their own or family's life (Ullman \& Filipas, 2001). The victims feel sensitive about the bias shown to their experiences and avoid reporting resulting in a depressive state of mind. In such cases, hiding is used to be a coping strategy by the victims (Marsh et al., 2009). The victims' perspective here shows that talking about harassment is discouraging and stifling. They want people around them to trust them and listen to their stories. They want to live their lives bravely and purposefully with no threat to their lives or integrity. Sharing different coping strategies through tweets show the victims' solidarity and empathy for other victims and a desire to support them live a better life.

According to Van Dijk's (2000) definition, the discourse on \#MeToo is definitely an ideological discourse as it 
has a certain structure and schema. It assures their group-ness and being a victim is the membership criteria. The members of this group are talking about gender disparity and know their basic human rights. The shared social experiences of the victims and their mental and context models get expression through the discourse on \#MeToo. As ideology gets created, expressed and presented by a social group collectively (Van Dijk, 2000), e.g., discourse on \#MeToo.

The victims' perspective on harassment reflects a dire need to accept and acknowledge harassment for the psychological healing of the victims. This seems to be one of the biggest support to the victims to endorse their stories and believe them as the discourse does not give any hint to the victims' desire or recommendation for a certain level of punishment for the perpetrators. The victims' friendly conduct is misinterpreted as sexual consent or a willingness for a sexual act, which in fact it is not. "Victim blaming" (Burn, 2018) is deemed cruel and used as a trick by the perpetrators to avoid accepting guilt by shifting the focus of attention from perpetrator to the victim.

The victims' perspective shows that harassment cannot be limited to the physical act but it can occur verbally or in any form that makes one feel uncomfortable. There are as many possibilities of online harassment as offline harassment. It can occur in childhood and in mature age as well. There can be shadows of insecurity lurking both inside and outside of the home.

The victims' discourse points out the need for making homes and work environments safe from the abuse of power and any form of exploitation. It is essential to create a support mechanism for the victims to recourse on.

We find a fair amount of similarity between the definition of harassment in existing literature including law and in the discourse created by the victims on \#MeToo. But there are certain terms like an act of "sexual nature" that is hard to be defined perfectly. The victims' view is that the listing of sexual acts be withdrawn in favor of it being any act or word that creates uneasiness and discomfort. The basic emphasis of the victims is an acknowledgment which is missing in the existing literature.

Even law creates checklists to rule about the occurrence of sexual harassment, but the victims do not take it as a matter of jurisdiction. At the organizational level, harassment is taken to be related to work environment and mutual relationships but the victims consider emotional and psychological well-being more important than the attention given to the betterment of environmental factors. Post harassment traumatic effects are of foremost importance to the victims. The victims' discourse implicitly hints that the basic requirement is to amend the view of harassment to tackle it in a better way. There is, perhaps, a need to regulate even family and personal lives.

The prevalent discourse does not talk about the emotional well-being of the victims that points to the need to broaden its view about the importance of solace. Some tweets show regret about the non-availability or lack of workability of the support mechanism.

Twitter is one of the most popular forms of social media that has contributed abundantly in spreading news globally within the blink of an eye. Its accessibility has surpassed print media and the conversation style motivates people to take part in the discussion. The features of Twitter have played a great role in shaping the discourse on \#MeToo. It encouraged the victims to share their stories and give vent to their suppressed feelings. Though Twitter does not give a detailed description of the stories and fails to provide access to the real identity of the posters. The para verbal elements sometimes create ambiguity and do not convey the intended meaning to the receivers.

The significance of the study lies in that it brings out the unfiltered voice of the victims. It is uninfluenced by any mediating influence. Another important aspect attached to \#MeToo is its continuation. It proved to be much more than an ordinary Twitter moment and time has failed to diminish its significance.

\section{References}

Abbey, A. (2002). Alcohol-related sexual assault: A common problem among college students. Journal of Studies on Alcohol, (s14), 118-128. https://doi.org/10.15288/jsas.2002.s14.118

Alo, M., \& Orimogunje, A. (2013). Discourse strategies and ideology in selected radio lead news of Osun State Broadcasting Corporation, Nigeria. 3L: Language, Linguistics, Literature, 19(2), 111-123.

Ana, O. S. (1997). Empirical analysis of anti-immigrant metaphor in political discourse. U. Penn Working Papers in Linguistics, 4(1).

Azad, O. (2013). Critical discourse analysis of 20:30 news broadcasting. Modern Journal of Language Teaching Methods, 3(2), 78-98.

Bever, L., \& Ohlheiser, A. (2017, December 06). Time's Person of the Year: 'The Silence Breakers' for speaking 
out against sexual harassment. The Washington Post. Retrieved from https:/www.washingtonpost.com/news/the-intersect/wp/2017/12/06/times-person-of-the-year-the-silence-b reakers-for-speaking-out-against-sexual-harassment/?noredirect=on\&utm_term $=.9 \mathrm{e} 2 \mathrm{c} 243 \mathrm{f} 9017$

Bilal, H. A., Ahsan, H. M., Gohar, S., Younis, S., \& Awan, S. J. (2012). Critical discourse analysis of political TV talk shows of Pakistani media. International Journal of Linguistics, 4(1), $203-219$. https://doi.org/10.5296/ijl.v4i1.1425

Burke, L. (2018, March 09). The \#MeToo shockwave: How the movement has reverberated around the world. The Telegraph. Retrieved from https:/www.telegraph.co.uk/news/world/metoo-shockwave/

Carla the Viking [carlatheviking]. (2017, Oct 15). But I'm not telling my story because I did that already and they told me I was lying for attention. \#MeToo [Tweet]. Retrieved from https://witter.com/carlatheviking/status/919708963045871616

Carlsen, A., Salam, M., Miller, C. C., Lu, D., Ngu, A., Patel, J. K., \& Wichter, Z. (2018). \#MeToo brought down 201 powerful men. Nearly half of their replacement are women. The New York Time. Retrieved from https:/www.nytimes.com/interactive/2018/10/23/us/metoo-replacements.html

Chiluwa, I. (2012). Social media networks and the discourse of resistance: A sociolinguistic CDA of Biafra online discourses. Discourse \& Society, 23(3), 217-244. https://doi.org/10.1177/0957926511433478

Claudia [hernameisreyo]. (2017, Oct 15). People seem to forget that those catcalls at women really ARE sexual harassment [Tweet]. Retrieved from https://twitter.com/hernameisreyo/status/919712917968359425

Döring, N. (2000). Feminist views of cybersex: Victimization, liberation, and empowerment. Cyber Psychology and Behavior, 3, 863-884. https://doi.org/10.1089/10949310050191845

Genée [genee216]. (2017, Oct 15). Molested from the ages of 3-5 by my baby sitters kids (teens) and then raped after homecoming. Retrieved from https://twitter.com/genee216/status/919710968405544961

Golmohammadi, S., Suluki, S., Daneshmand, F., \& Salahshoor, F. (2014). Socio-Cognitive perspective to the analysis of the strategic features of the discussion section of research articles in applied linguistics: Native vs. non-native researchers. Procedia-Social and Behavioral Sciences, 98, 604-613. https://doi.org/10.1016/j.sbspro.2014.03.457

Harassment. (2010). In the Protection against Harassment of Women at the Workplace Act 2010 (Act IV of 2010). Retrieved from http://punjablaws.gov.pk/laws/2426a.html

Harassment. (2018). Sexual harassment. Australian Human Rights Commission. Retrieved from https://www.humanrights.gov.au/our-work/sex-discrimination/projects/sexual-harassment-0

Harassment. (n.d.). What is Harassment? Retrieved from https://www.chrc-ccdp.gc.ca/eng/content/what-harassment-1

Harassment. (n.d.). What is sexual harassment? Stanford University. Retrieved from https://harass.stanford.edu/be-informed/what-sexual-harassment

Heymann, J., \& Vogelstein, R. (2017, November 17). When sexual harassment is legal. Fortune. Retrieved from http://fortune.com/2017/11/17/sexual-harassment-legal-gaps/

Holroyd-Leduc, J. M., \& Straus, S. E. (2018). \#MeToo and the medical profession. CMAJ: Canadian Medical Association Journal, 190(33), E972-E973. https://doi.org/10.1503/cmaj.181037

HRMP. (n.d.). Sexual harassment, different countries. Retrieved from http:/hrmpractice.com/sexual-harassment-countries/

Jahangir, R. (2018, April 19). Pakistani women use hashtag to expose scale of sexual abuse. Dawn. Retrieved from https://www.dawn.com/news/1364520

Lanece_sr [lanece_sr]. (2017, Oct 15). When I was in the 10th grade, a boy grabbed my butt so I punched him. Retrieved from https://witter.com/lanece_sr/status/919714466182377472

Lindahl, C. (2017, Oct 15). When I was 19, I worked at an office where I grabbed from behind from the delivery guy. Retrieved from https://witter.com/Sissy02468/status/919711224966930432

Loveday, J. (2017, December 01). Continuing the \#MeToo movement gives victims a voice. Odyssey. Retrieved from https://www.theodysseyonline.com/continuing-the-metoo-movement-gives-victims-voice

Marsh, J., Patel, S., Gelaye, B., Goshu, M., Worku, A., Williams, M. A., \& Berhane, Y. (2009). Prevalence of 
workplace abuse and sexual harassment among female faculty and staff. Journal of Occupational Health, 51(4), 314-322. https://doi.org/10.1539/joh.L8143

Martinez, B. (2017, Oct 15). I'm a gay when I decided to come out a friend cousin drugged me at a party and rapped me $r$... Retrieved from https://twitter.com/brendanmartine1/status/919709014505779200

Mehmood, R. (2018, April, 22). Pakistan's long \#MeToo movement. Aljazeera. Retrieved from https://www.aljazeera.com/.../pakistan-long-metoo-moment-180422151525450.html

Malone, S., \& Gibson, G. (2017, January 21). Women lead unprecedented worldwide mass protests against Trump. Reuters. Retrieved from https://www.reuters.com/article/us-usa-trump-women-idUSKBN15608K

Mendes, K., Ringrose, J., \& Keller, J. (2018). \# MeToo and the promise and pitfalls of challenging rape culture through digital feminist activism. European Journal of Women's Studies, 25(2), 236-246. https://doi.org/10.1177/1350506818765318

\#MeToo. (n.d.). Spread section. Know your meme. Retrieved from http://knowyourmeme.com $/ \mathrm{memes} / \mathrm{metoo}$

Mitchell, H., \& Hilary, W. (2017, Oct 15). I went to a dinner party at an acquaintance's house, got drunk, crashed on his sofa, I... Retrieved from https://twitter.com/Hilary_W/status/919714102863388672

NowThis [nowthisnews]. (2018, Apr 06). Life coach Tony Robbins says women are using \#MeToo to make themselves 'significant'-but this brave sexual abuse... Retrieved from https://twitter.com/nowthisnews/status/982389487836778496

Nuraddin, N. (2018). The representation of the\# Metoo movement in mainstream international media. Retrieved from http://www.diva-portal.org/smash/get/diva2:1227947/FULLTEXT01.pdf

Pasha, T. (2011). Islamists in the headlines: Critical discourse analysis of the representation of the Muslim Brotherhood in Egyptian newspapers. The University of Utah.

PettyJohn, M. E., Muzzey, F. K., Maas, M. K., \& McCauley, H. L. (2018, September 13). \#HowIWillChange: Engaging men and boys in the \#MeToo movement. Psychology of Men \& Masculinity. https://doi.org/10.1037/men0000186

Ramanathan, R., \& Tan, B. H. (2015). Application of critical discourse analysis in media discourse studies. $3 L$ : The Southeast Asian Journal of English Language Studies, 21(2), 57-68 Retrieved from https://www.researchgate.net/publication/283712478_Application_of_Critical_Discourse_Analysis_in_Me dia_Discourse_Studies

Sahgal, P., \& Dang, A. (2017). Sexual harassment at workplace. Economic \& Political Weekly, 52(22), 49.

Scott, E. (2017, December 07). The marginalized voices of the \#MeToo movement. The Washington Post. Retrieved

from https://www.washingtonpost.com/news/the-fix/wp/2017/12/07/the-marginalized-voices-of-the-metoo-move ment/?noredirect $=$ on\&utm_term $=.0 \mathrm{f} 433 \mathrm{ff5ff65}$

Sexual harassment. (n.d.). Sexual harassment. In Cambridge Dictionary online. Retrieved from https://dictionary.cambridge.org/dictionary/english/ sexual harassment

Shah, S. (2018). Celebrities accused of sexual harassment world over. The News. Retrieved from https://www.thenews.com.pk/print/309555-celebrities-accused-of-sexual-harassment-world-over

Singh, A. (2017, October 25). \#Me too becomes a movement for victims of sexual assault. Revolt. Retrieved from https://revolt.tv/stories/2017/.../25/metoo-movement-victims-sexual-assault-0700e 7c5...

Smith, K. (2018, February 03). A male backlash against \#MeToo is brewing. New York Post. Retrieved from https://nypost.com/2018/02/03/a-male-backlash-against-metoo-is-brewing/

The Guardian. (2016, November, 9). The Guardian view on President-elect Donald Trump: a dark day for the world. Retrieved from https://www.theguardian.com/commentisfree/2016/nov/09/the-guardian-view-on-president-elect-donald-tru mp-a-dark-day-for-the-world

Van Dijk, T. A. (2000). Ideology and discourse: A multidisciplinary introduction. Pompeu Fabra University, Barcelona. Retrieved from http://www.discourses.org/OldBooks/Teun\%20A\%20van\%20Dijk\%20-\%20Ideology\%20and\%20Discourse .pdf

Witkowska, E. (2005). Sexual harassment in schools. Prevalence, structure and perceptions. National institute 
of working life. Retrieved from https://core.ac.uk/download/pdf/16312411.pdf

Wood, M. K. (2018). Language in digital activism: exploring the performative functions of\# MeToo Tweets. Diggitmagazine com.

Retrieved from https://www.diggitmagazine.com/academic-papers/language-digital-activism-exploring-performative-functi ons-metoo-tweets

\section{Copyrights}

Copyright for this article is retained by the author, with first publication rights granted to the journal.

This is an open-access article distributed under the terms and conditions of the Creative Commons Attribution license (http://creativecommons.org/licenses/by/4.0/). 